\title{
Negative regulatory approaches to the attenuation of Toll-like receptor signaling
}

\author{
Muhammad Ayaz Anwar, Shaherin Basith and Sangdun Choi \\ Toll-like receptors (TLRs) are pivotal components of the innate immune response, which is responsible for eradicating invading \\ microorganisms through the induction of inflammatory molecules. These receptors are also involved in responding to harmful \\ endogenous molecules and have crucial roles in the activation of the innate immune system and shaping the adaptive immune \\ response. However, TLR signaling pathways must be tightly regulated because undue TLR stimulation may disrupt the fine \\ balance between pro- and anti-inflammatory responses. Such disruptions may harm the host through the development of \\ autoimmune and inflammatory diseases, such as rheumatoid arthritis and systemic lupus erythematosus. Several studies have \\ investigated the regulatory pathways of TLRs that are essential for modulating proinflammatory responses. These studies \\ reported several pathways and molecules that act individually or in combination to regulate immune responses. In this review, \\ we have summarized recent advancements in the elucidation of the negative regulation of TLR signaling. Moreover, this review \\ covers the modulation of TLR signaling at multiple levels, including adaptor complex destabilization, phosphorylation and \\ ubiquitin-mediated degradation of signal proteins, manipulation of other receptors, and transcriptional regulation. Lastly, \\ synthetic inhibitors have also been briefly discussed to highlight negative regulatory approaches in the treatment of \\ inflammatory diseases.
}

Experimental \& Molecular Medicine (2013) 45, e11; doi:10.1038/emm.2013.28; published online 22 February 2013

Keywords: inflammatory diseases; inhibitors; innate immune system; miRNA; Toll-like receptors

\section{INTRODUCTION}

The innate immune system, an organism's first line of defense against invading pathogens, employs a variety of transmembrane and secreted molecules, known as pattern recognition receptors, for the sensing of microbes, the activation of adaptive immunity and complement system, apoptosis, and the induction of proinflammatory mediators. Among the pattern recognition receptors, Toll-like receptors (TLRs) occupy a prominent place. TLRs were initially described as being involved in the embryonic development of Drosophila. ${ }^{1}$ Later, when a homolog of Drosophila Toll, TLR4, was cloned in 1997, it was confirmed that Toll signaling pathways are conserved in humans, where TLRs have important roles in the activation of adaptive immunity. ${ }^{2}$ Soon after the discovery of TLR4, it became evident that lipopolysaccharide (LPS), a bacterial cell membrane component, is recognized by TLR4 (pattern recognition receptor), establishing a link between pathogen-associated molecular patterns (PAMPs) and TLRs. ${ }^{3-5}$ PAMPs are conserved molecular signatures found in different microbes, such as bacteria, viruses, fungi, and protozoa. Different PAMPs are recognized by different TLRs (Table 1) and include the following: LPS and lipoteichoic acid (all recognized by TLR4); peptidoglycan in cell walls, lipoproteins in bacterial capsules, and zymosan (all recognized by TLR2 following heterodimerization with TLR1 or TLR6); flagellin (recognized by TLR5); unmethylated bacterial or viral CpG DNA (recognized by TLR9); viral RNA (single-stranded RNA recognized by TLR7 and TLR8; double-stranded RNA recognized by TLR3); and bacterial RNA (23S rRNA recognized by the orphan receptor TLR13). ${ }^{6}$

TLRs are classified as members of the Toll/interleukin (IL)-1 receptor (TIR) superfamily based on their structural similarities. All TLRs possess a common architecture consisting of three domains: a leucine-rich ectodomain for PAMP recognition; an intracytoplasmic TIR endodomain for adaptor recruitment, such as myeloid differentiation 88 (MyD88), MyD88-adaptor-like (MAL), TIR-domain-containing adaptor-inducing interferon- $\beta$ (TRIF), and TRIF-related adaptor

Department of Molecular Science and Technology, Ajou University, Suwon, Republic of Korea

Correspondence: Professor S Choi, Department of Molecular Science and Technology, Ajou University, Woncheon-dong, Yeongtong-gu, Suwon 443-749, Republic of Korea.

E-mail: sangdunchoi@ajou.ac.kr

Received 13 January 2013; accepted 15 January 2013 
Table 1 TLRs and their ligands, adaptor usage, and cytokine production

\begin{tabular}{|c|c|c|c|c|}
\hline \multirow[b]{2}{*}{ Receptor } & \multicolumn{2}{|r|}{ Ligands } & \multirow{2}{*}{$\begin{array}{l}\text { Signal } \\
\text { adaptor }\end{array}$} & \multirow[b]{2}{*}{ Production } \\
\hline & PAMPS & $D A M P S$ & & \\
\hline $\begin{array}{l}\text { TLR1/ } \\
\text { TLR2 }\end{array}$ & $\begin{array}{l}\text { Lipoproteins/ } \\
\text { triacyl lipoproteins }\left(\mathrm{Pam}_{3} \mathrm{CSK}_{4}\right)\end{array}$ & Not determined & MAL/MyD88 & Proinflammatory cytokines \\
\hline $\begin{array}{l}\text { TLR2/ } \\
\text { TLR6 }\end{array}$ & $\begin{array}{l}\text { Diacylated lipoproteins, lipotei- } \\
\text { choic acid, zymosan }\end{array}$ & $\begin{array}{l}\text { Heat-shock proteins such as HSP60, HSP70, } \\
\text { and Gp96; HMGB1; ECM fragments such as } \\
\text { versican and hyaluronic acid }\end{array}$ & MAL/MyD88 & Proinflammatory cytokines \\
\hline TLR3 & dsRNA (poly I:C) & mRNA & TRIF & $\begin{array}{l}\text { Proinflammatory cytokines, } \\
\text { type I IFNs }\end{array}$ \\
\hline TLR4 & $\begin{array}{l}\text { Lipopolysaccharides, viral } \\
\text { envelope proteins }\end{array}$ & $\begin{array}{l}\text { Heat-shock proteins such as HSP22, HSP 60, } \\
\text { HSP70, HSP72, and Gp96; HMGB1; ECM } \\
\text { fragments such as versican, hyaluronic acid, } \\
\text { heparin sulfate and fibronectin; tenascin-C; } \\
\text { oxidized phospholipids; } \beta \text {-defensin } 2\end{array}$ & $\begin{array}{l}\text { MAL/MyD88 } \\
\text { TRAM/TRIF }\end{array}$ & $\begin{array}{l}\text { Proinflammatory cytokines } \\
\text { Type I IFNs }\end{array}$ \\
\hline TLR5 & Flagellin & Not determined & MyD88 & Proinflammatory cytokines \\
\hline TLR6/ & Not determined & Amyloid- $\beta$, oxidized low-density lipoprotein & MyD88 & Proinflammatory cytokines \\
\hline TLR4 & & & TRIF & Type I IFNs \\
\hline TLR7 & $\begin{array}{l}\text { SSRNA, imidazoquinolines } \\
\text { (R848), guanosine analogs } \\
\text { (loxoribine) }\end{array}$ & ssRNA (immune complex) & MyD88 & $\begin{array}{l}\text { Proinflammatory cytokines, } \\
\text { type I IFNs }\end{array}$ \\
\hline TLR8 & $\begin{array}{l}\text { ssRNA, imidazoquinolines } \\
\text { (R848) }\end{array}$ & ssRNA (immune complex) & MyD88 & $\begin{array}{l}\text { Proinflammatory cytokines, } \\
\text { type I IFNs }\end{array}$ \\
\hline TLR9 & $\begin{array}{l}\text { Unmethylated CpG DNA, CpG } \\
\text { oligodinucleotides, hemozoin }\end{array}$ & Chromatin IgG complex & MyD88 & $\begin{array}{l}\text { Proinflammatory cytokines, } \\
\text { type I IFNs }\end{array}$ \\
\hline TLR10 & Profilin-like molecule & Not determined & MyD88 & Proinflammatory cytokines \\
\hline TLR11 & $\begin{array}{l}\text { Profilin-like molecule, uro- } \\
\text { pathogenic bacteria }\end{array}$ & Not determined & MyD88 & Proinflammatory cytokines \\
\hline TLR13 & Bacterial $23 S$ rRNA & Not determined & MyD88 & Proinflammatory cytokines \\
\hline
\end{tabular}

Abbreviations: DAMP, danger-associated molecular patterns; dsRNA, double-stranded RNA; ECM, extracellular matrix; Gp96, glycoprotein 96; HMGB1, high-mobility group box 1; HSP, heat-shock protein; IFN, interferon; IgG, immunoglobin G; MAL, MyD88 adaptor like; MyD88, myeloid differentiation 88; PAMP, pathogenassociated molecular patterns; poly(I:C), polyinosinic-polycytidylic acid; sSRNA, single-stranded RNA; TLR, Toll-like receptors; TRAM; TRIF-related adaptor molecule; TRIF, TIR-domain-containing adaptor-inducing interferon- $\beta$.

molecule (TRAM); and a transmembrane domain that connects the ectodomain to the endodomain. The expression patterns of the TLRs are highly selective in accordance with their PAMP recognition properties. TLRs, such as TLR1, TLR2, TLR4, TLR5, and TLR6, are predominantly expressed on the cell surface because they are involved in the recognition of cell surface molecules, whereas TLR3, TLR7, TLR8, TLR9, TLR11, and TLR13 are expressed in endosomal compartments because they are involved in nucleic acid recognition. ${ }^{6-8}$ However, some TLRs, for example, TLR2 and 4, are removed from the cell surface after ligand binding and are then recruited to macrophage phagosomes. ${ }^{9,10}$ Upon ligand binding followed by dimerization of TLRs, TIR domain recruits adaptor molecules, which propagate signals that converge at nuclear factor (NF)- $\kappa \mathrm{B}$ (Figure 1) and induce the production of interferons (IFNs) and proinflammatory cytokines, such as tumor necrosis factor $\alpha$ (TNF- $\alpha$ ), IL-1, and IL-6. ${ }^{8}$ This proinflammatory response protects the organism against microbes, but after eliminating the threat, the system must return to a homeostatic state.
Failure to restore homeostasis by uncontrolled expression of inflammatory mediators may render the organism prone to develop septic shock and autoinflammatory diseases, such as rheumatoid arthritis and systemic lupus erythematosus (SLE). Therefore, controlling the entire inflammatory response is essential for removing invading microbes without damaging the host. To regulate the response, the cell has evolved numerous ways to maintain balance, including the removal of receptors from the cell surface, expression of dominant-negative regulators, ubiquitin-proteasome-mediated degradation of intermediate molecules, chromosomal remodeling, and attenuation of the expression of different adaptors and inflammatory molecules. All these activities act in synergy and play crucial roles in regulating the inflammatory response. In this review, we have covered the negative regulatory mechanisms that cooperate to maintain TLR-mediated signaling in homeostasis.

\section{PHYSIOLOGICAL IMPORTANCE OF TLRS}

Physiologically, TLRs are critical for the induction of the innate and adaptive immune systems to combat invading 


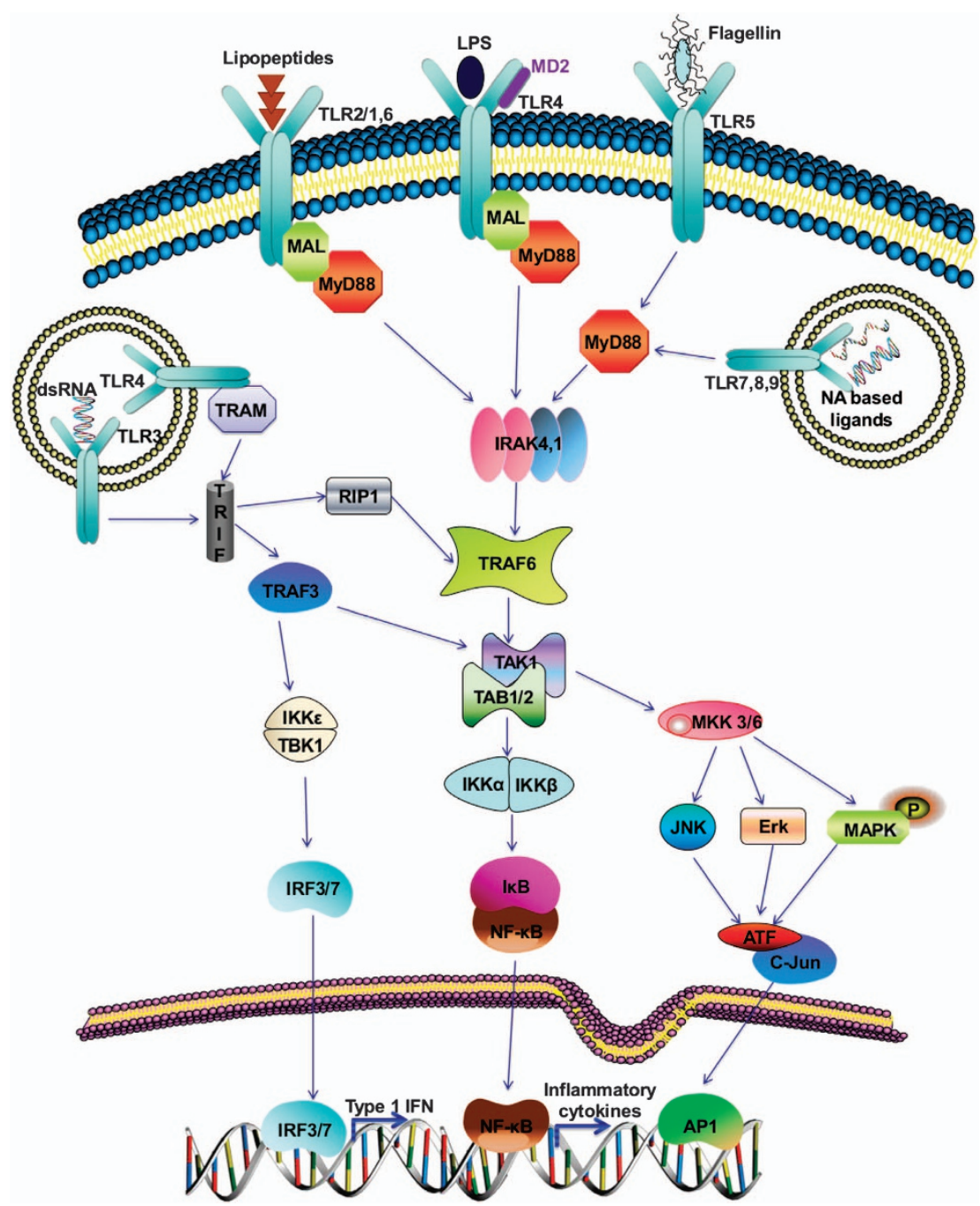

Figure 1 Overview of the Toll-like receptor (TLR) signaling pathway. When TLRs are stimulated by their respective ligands, they dimerize and recruit downstream adaptor molecules, such as myeloid differentiation primary-response protein 88 (MyD88), MyD88-adaptor-like (MAL), Toll/interleukin (IL)-1 receptor (TIR)-domain-containing adaptor-inducing interferon- $\beta$ (TRIF), TRIF-related adaptor molecule (TRAM), which activate other downstream molecules leading to the activation of signaling cascades that converge at the nuclear factor- $\mathrm{B}$ $(\mathrm{NF}-\mathrm{KB}$ ), interferon (IFN) response factors (IRFs) and mitogen-activated protein (MAP) kinases. These molecules induce the transcription of several proinflammatory molecules, such as interleukin (IL)-6, IL-8, IL-12, and tumor necrosis factor $\alpha$ (TNF- $\alpha$ ). The secretion of these molecules counters the threat posed by microbes and helps activate other immune components. AP1, activator protein 1; ATF, activating transcription factor; dsRNA, double-stranded RNA; ERK, extracellular signal-regulated kinase; IKK, inhibitor of kappa light polypeptide gene enhancer in B-cell kinase; IRAK, IL-1 receptor-associated kinase; JNK, C-Jun N-terminal kinase; LPS, lipopolysaccharide; MD, myeloid differentiation factor; MKK, MAPK kinase; NA, nucleic acid; TAB, transforming growth factor- $\beta$-activated kinase 1/MAP3K7binding protein; TAK, transforming growth factor-activated kinase; TRAF, tumor necrosis factor receptor-associated factor; RIP1, receptorinteracting protein 1 .

microorganisms. ${ }^{11,12}$ These receptors mount immune responses against pathogens on the skin and in the mucosa of the respiratory, gastrointestinal, and urogenital tracts. TLRs activate multiple pathways leading to the secretion of proinflammatory molecules (including TNF- $\alpha$, IL-1, and IL-6) and chemokines (for example, monocyte chemoattractant protein 1 (MCP-1), MCP-3, and granulocyte-macrophage colony-stimulating factor). TLRs have been correlated with transcriptional and posttranslational regulation (proteolytic cleavage and secretion) of antimicrobial factors, such as defensins $\alpha$ and $\beta$, phospholipase A2, and lysozyme. ${ }^{13}$ In addition, TLRs are involved in the opsonization of microorganisms and optimize the defense against invading microorganisms by regulating the release of peroxy radicals and nitric oxide. ${ }^{14,15}$ TLRs on the endothelial cell surface indirectly promote leukocyte homing to the inflammatory region by enhancing the expression of the leukocyte adhesion molecules E-selectin and intercellular adhesion molecule $1 .^{16}$ 
Different antiviral molecules, such as IFN- $\alpha$ and IFN- $\beta$, are also overexpressed by TLRs in hematopoietic and stromal cells to combat viral infections. ${ }^{17}$ Moreover, as described in recent reports, TLRs induce apoptosis through the production of certain proapoptotic factors (Fas-associated death domain, caspase-8, protein kinase R), which accounts for an important defense mechanism against some incurable pathogenic infections. ${ }^{18}$ The activation of antigen-presenting cells by TLRs is also decisive in many essential processes that lead to the development of adaptive immune responses, such as T-cell activation, enhancement of antigen presentation, increased expression of accessory molecules (for example, cluster of differentiation $80(\mathrm{CD} 80))$, and suppression of regulatory T cells activity. ${ }^{19}$ TLR-dependent activation is also important for B-cell proliferation and maturation during the infection process. ${ }^{20}$ Thus, accumulating evidence supports an important role for the TLRs in the initiation and development of the inflammatory process in response to various pathogens.

Furthermore, pathogen recognition by TLRs is now considered the midpoint in the initiation of the adaptive immune response, the organism's second line of defense. ${ }^{21}$ Apart from their protective role, TLRs are also implicated in the pathogenesis of the autoimmune diseases, such as SLE, rheumatoid arthritis, atherosclerosis, and certain other disorders. ${ }^{22}$ However, recent data point to a dual function of TLRs as antitumor and protumor modulators, ${ }^{23}$ such findings indicate the need for further studies to delineate the precise role of TLRs in tumor biology. TLR functions may depend on the cell type and the cell context where they express. Other aspects that influence TLR activity include the influence of the extracellular matrix, coreceptors, and cross-talk between different signaling pathways.

\section{NEGATIVE REGULATION OF TLRS}

Following TLR activation and establishment of the inflammatory response against invading pathogens, there must be a checkpoint where TLR signaling is abolished and the system is returned to a normal physiological state to avoid a harmful response towards the host immune system. To date, numerous negative regulatory molecules have been characterized. In the following sections, we have discussed a few potent negative regulatory mechanisms of TLR signaling at different levels (Figure 2).

\section{Soluble and decoy factors in TLR regulation}

If the immune system does not respond appropriately during a bacterial challenge, septic shock occurs, leading to multiple organ failure and death of the host. Sustained activation and overactivation of TLRs also results in the pathogenesis of autoimmune, chronic inflammatory, and neoplastic diseases. $^{24,25}$ Therefore, pro- and anti-inflammatory responses must be balanced. Treatment with soluble receptors is one such physiological approach for modulating the immune response.

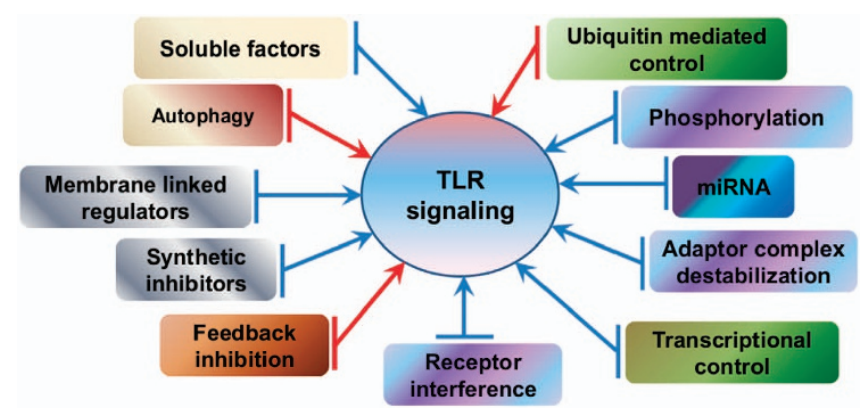

Figure 2 Regulatory checkpoints in the Toll-like receptor (TLR) pathway. Subsequent to stimulation with their cognate ligands, TLRs induce several mediators converging at nuclear factor- $\kappa B$ (NF-kB), which mobilizes the transcription of inflammatory genes. This helps the host prepare to fight the microbial threat. After eliminating the threat, the cell must turn off the expression of inflammatory mediators. Sustained activation and overactivation of TLRs are usually accompanied by deleterious consequences for the host. To prevent these consequences, the cell employs a variety of mechanisms to regulate TLR signaling, including decoy factors, adaptor modification, ubiquitin-mediated degradation, promoter state alteration, and translation disruption. All these mechanisms, individually or in combination, exert the effect of controlling inflammation and supporting the system to regain its normal state (arrows in red indicate the irreversible regulation, whereas the others show the reversible regulation).

It has been reported that blood monocytes release a constant amount of the soluble form of TLR2, which is produced during post-translational modification events. ${ }^{26}$ In the presence of soluble form of TLR2, decreased amounts of IL- 8 and TNF- $\alpha$ are seen. This effect may be associated with the interaction between soluble form of TLR2 and soluble CD14, a coreceptor of TLR2 and TLR4; however, this needs to be further investigated. ${ }^{27}$ The soluble form of TLR4 also inhibits TLR4-mediated signaling, possibly by interfering with receptor-ligand associations. ${ }^{28}$ In a study involving a mouse macrophage cell line, the presence of soluble form of TLR4 significantly reduced LPS-induced nuclear factor- $\kappa \mathrm{B}$ $(\mathrm{NF}-\mathrm{kB})$ activation and TNF production, suggesting that soluble form of TLR4 is involved in regulating TLR signaling. In addition, soluble CD14 is involved in regulating TLR4-induced cytokine release, and soluble ST2 is involved in regulating TLR1- and TLR4-induced cytokine release..$^{29,30}$ Soluble CD14 binds directly to LPS and alters the signaling patterns, whereas soluble ST2 inhibits the overexpression of TLR1 and TLR4. Thus, hypoexpression leads to decreased production of proinflammatory mediators.

\section{Membrane-associated protein regulators}

In addition to soluble factors, transmembrane protein receptors are also involved in the negative regulation of TLR signaling, for example, single immunoglobulin IL-1R-related molecule, ST2L, and radioprotective 105 (RP105). Single immunoglobulin IL-1R-related molecule belongs to the TIR superfamily that binds to TIR components in a ligand- 
dependent manner and hinders the recruitment of adaptors. ${ }^{31}$ Single immunoglobulin IL-1R-related molecule-deficient mice, when stimulated with ligands, produce increased volumes of inflammatory cytokines, indicating the regulatory importance of single immunoglobulin IL-1R-related molecule. The membrane-bound form of ST2, ST2L, also regulates the overactivation of TLR2, TLR4, and TLR9 by preventing downstream receptor-adaptor complex formation through its BB loop. ${ }^{32,33}$ Mice lacking ST2L fail to develop immune tolerance to these ligands, resulting in fatal consequences. Radioprotective 105 is a TLR homolog that is expressed on different antigen-presenting cells, lacks the signaling domain, and specifically inhibits TLR4-mediated signaling. Radioprotective 105, along with its helper molecule myeloid differentiation factor 1 , binds to the TLR ectodomain and prevents ligand binding to the TLR4, thereby inhibiting signaling. Cells lacking radioprotective 105 respond strongly to LPS, thus implying a negative regulatory role for this protein. ${ }^{34}$

\section{Negative regulators of the adaptor complex}

Several adaptor proteins, such as MyD88, TIRAP/MAL, TRIF, and TRAM, are involved in efficient signaling by TLRs, ${ }^{35}$ thus providing an opportunity for fine control. This signal propagation can be prevented by blocking the formation of the TIR-domain complex. Several adaptor variants serve as negative regulators of complex formation, preventing downstream signaling pathways. Among these molecules, the TRAM adaptor with Golgi dynamics (GOLD) domain is a variant of TRAM that competes with TRAM for TRIF binding. Once TRAM adaptor with GOLD domain is in the bound form, it inhibits the TRIF-dependent pathway. ${ }^{36}$ To prevent the LPSinduced overactivation of TLR4, TRAM adaptor with GOLD domain is also involved in the internalization of TLR4 to the endosomes for subsequent degradation. In association with transmembrane emp24 protein transport domain containing 7, another GOLD domain-containing protein, TRAM adaptor with GOLD domain mediates disruption of the TRAM-TRIF complex and inhibits TLR4 signaling from the endosome upon LPS stimulation. ${ }^{37}$

To inhibit competitively MyD88 and regulate inflammatory responses, flightless I-like homolog negatively disrupts the TLR4-MyD88 complex. RNAi-mediated reduction of flightless I-like homolog leads to the overexpression of TLR-mediated inflammatory cytokines, thus highlighting the role of flightless I-like homolog in innate immune signaling. ${ }^{38}$ Another TIRdomain-containing protein, sterile $\alpha$ - and armadillo-motifcontaining protein (SARM), is also involved in the blocking of the TRIF complex formation by direct binding to TRIF, rendering TRIF unavailable after LPS treatment. ${ }^{39}$ Although the sterile $\alpha$-motif domain is necessary for inhibition of the TRIF-dependent pathway, the molecular mechanism of inhibition is largely unknown. In another study, MAL, a positive regulator of TLR2 and TLR 4 signaling, has been reported to bind with interferon response factor-7 (IRF-7) and cease its activation, but not with IRF-3, and to block specifically TLR3-induced IFN- $\beta$ production while leaving the production of IL- 6 and TNF- $\alpha$ unaltered. Results from several biochemical experiments have shown that MAL interacts with IRF-7 through the positive regulatory domains I-III of the enhancer element of the IFN- $\beta$ gene following polyinosinic-polycytidylic acid stimulation. This study pointed out a new regulatory potential in TLR signaling. ${ }^{40}$ TRIF, another adaptor protein in TLR3 and TLR4 signaling, is also known for its negative effects on other TLRs. In a study, when dendritic cells (DCs) were induced with Eimeria tenelladerived antigen, it was observed that TRIF impeded TLR signaling by degrading activated TLRs, including TLR4, TLR5, TLR7, TLR8 and TLR9. ${ }^{41}$ TRIF knockout mice showed a dramatic increase in cytokine production and expression of costimulatory molecules and other inflammatory mediators. This study assigns a new role for TRIF in regulating inflammatory responses.

Recently, it was found that docking protein 3 (DOK3) impedes LPS signaling in macrophages. DOK3 was found to be degraded by ubiquitin-mediated proteolysis along with son of sevenless homolog 1 in response to LPS stimuli, thus limiting the activation of extracellular signal-regulated kinase (ERK). Macrophages from DOK3-deficient mice showed increased son of sevenless homolog 1 expression and NF- $\mathrm{KB}$ induction. ${ }^{42}$ The DOK3-deficient cells also showed increased expression of Src homology phosphatase 1, IL-1 receptorassociated kinase M (IRAK-M), and suppressor of cytokine signaling 1, required for TLR tolerance, implying that DOK3 delays tolerance to the endotoxin. Furthermore, it is also hypothesized that DOK3 may interact with tumor progression locus 2 and interfere with ERK activation. ${ }^{43,44}$ These studies assign multiple roles to DOK3 in regulating TLR signaling. B-cell adaptor for phosphoinositide 3 kinase was initially considered to mediate B-cell receptor signaling and cell survival. Recently, the function of B-cell adaptor for phosphoinositide 3 kinase was ascribed to a cryptic TIR domain, connecting TLR signaling to the phosphatidylinositol 3-kinase (PI3K)/Akt signaling cascade, resulting in the regulation of TLR signaling by interfering with adaptors such as MyD88 and MAL, as well as activation of the PI3KAkt pathways. Therefore, B-cell adaptor for phosphoinositide 3 kinase-mediated regulation of TLR signaling limits the production of proinflammatory cytokines, such as IL-6, IL-12, and TNF- $\alpha$, as well as inflammatory responses associated with TLR4 and 9 in vivo. This hypothesis is supported by the findings of a study involving B-cell adaptor for phosphoinositide 3 kinase-deficient mice stimulated with TLR ligands, which produce exaggerated inflammatory responses. ${ }^{45}$

\section{Role of ubiquitination/deubiquitination in signaling attenuation}

Ubiquitination is a primary mechanism for shutting down signaling in cells at different stages by proteasome-mediated degradation. Tumor necrosis factor receptor-associated factor 
(TRAF)-family member-associated NF- $\kappa \mathrm{B}$ activator (TANK) binds to TRAF-binding protein and activates both NF- $\kappa \mathrm{B}$ and IRFs in vitro. However, TANK-deficient mice show increased $\mathrm{NF}-\kappa \mathrm{B}$ activity in response to TLR stimulation, rapidly leading to fatal glomerulonephritis. ${ }^{46}$ Cells with TANK ablation promote TRAF6 ubiquitination, which is necessary for NF- $\kappa \mathrm{B}$ activation, suggesting that TANK hinders TRAF6 ubiquitination in its bound form.

Another small heterodimer partner (SHP) induced by TLR activation inhibits TRAF6 ubiquitination, thereby leading to the suppression of TLR signaling. ${ }^{47}$ Cells lacking SHP secrete increased levels of TNF, IL-1 $\beta$, and IL-6 following LPS treatment. Moreover, when SHP-deficient mice are injected with bone-marrow-derived cells expressing SHP, the protection level increases during LPS-induced lethal shock. ${ }^{47}$ The ubiquitin-protein ligase class comprises several proteins, of which E3 ubiquitin ligase family is a widely studied group of proteins that facilitates the degradation of MAL and TRAF. ${ }^{48}$ By knocking out the Tyro3, Axl, and Mer receptor tyrosine kinase from DCs, TLR stimulation resulted in higher levels of inflammatory cytokines compared with those in wild-type cells. Further studies have shown that suppressor of cytokine signaling 1 and suppressor of cytokine signaling 3 are induced by signal transducers and activators of transcription 1 (STAT1), demonstrating Tyro3, Axl, and Mer receptor-mediated inhibition of TLR-induced cytokine production.

An ovarian tumor domain-containing deubiquitinase, deubiquitinating enzyme A, also acts as a suppressor of type I IFN production. ${ }^{49}$ Deubiquitinating enzyme A selectively mediates the cleavage of K63-linked polyubiquitin chains from TRAF3 to suppress TLR-induced type I IFN production, rendering $\mathrm{NF}-\kappa \mathrm{B}$ activation unaffected. PDZ and LIM domain protein 2 hinders TLR signaling by degradation of the NF- $\kappa \mathrm{B}$ p65 subunit. ${ }^{50}$ This inhibitory effect is mediated by promoting K48-linked polyubiquitination on p65 and sequestering p65 to nuclear promyelocytic leukemia bodies abundant with $26 \mathrm{~S}$ proteasomes. Following TLR stimulation, PDZ and LIM domain protein 2-deficient cells fail to degrade p65, thereby culminating in high levels of inflammation. IRF3 is controlled by ubiquitination-mediated peptidyl-prolyl cis-trans isomerase NIMA-interacting 1. Peptidyl-prolyl cis-trans isomerase NIMA-interacting 1 binds to phosphorylated IRF3 and inhibits type I IFN and antiviral responses. ${ }^{51}$ It has been hypothesized that binding and phosphorylation trigger conformational changes in the IRF3 structure, leading to ubiquitination degradation of the protein; thus, peptidylprolyl cis-trans isomerase NIMA-interacting 1 acts as an E3 ligase. ${ }^{52} \mathrm{~A}$ recent study reported that replication and transcription activator-associated ubiquitin ligase (RAUL) is linked to the ubiquitination of IRF3/7 and negatively regulates type I IFN. ${ }^{53}$ The replication and transcription activator of Kaposi's sarcoma-associated herpes virus also follows the same mechanism for degrading IRFs and escaping the immune response.
Further study into cell signaling regulation has shown that A20 negatively affects TLR signaling. A20-deficient mice show inflammation in various organs of the body, whereas doubleknockout mice with A20 and MyD88 deficiencies do not manifest these symptoms. Administration of antibiotics suppresses cachexia caused by the loss of A20, indicating that A20 significantly suppresses the inflammation caused by intestinal bacteria. ${ }^{54}$ In addition, A20 helps in the removal of K63-linked polyubiquitin chains on TRAF6 and aids mice in surviving LPS-induced endotoxin shock. Moreover, A20 inhibits inhibitor of $\kappa \mathrm{B}$ kinase (IKK) activation by transforming growth factor- $\beta$-activated protein kinase 1 (TAK1) without deubiquitin activity, suggesting that $A 20$ regulates $N F-\kappa B$ activation via multiple mechanisms. ${ }^{55}$ Ubiquitin-specific peptidase 4 (USP4) negatively regulates TRAF6, suppressing IL-1 $\beta$-induced NF- $\kappa B$ activation by removing polyubiquitin chains on TRAF6 in a deubiquitin activity-dependent manner. ${ }^{56}$ Loss of USP4 enhances cytokine production mediated by LPS and IL-1 $\beta$. Moreover, USP2a attenuates TLR and Sendai virus-mediated NF- $\kappa B$ activation by deubiquitination of TRAF6. ${ }^{57}$ Knockout and overexpression experiments have proven the negative effects of USP $2 \mathrm{a}$ on inflammatory responses. Another member of the USP family, USP25, also hinders the cellular inhibitor of apoptosis protein 2-induced K48-linked ubiquitin-mediated degradation of TRAF3, leading to the suppression of inflammatory responses. ${ }^{58}$

\section{Phosphorylation-mediated negative regulation of TLR signaling proteins}

TLR4 signaling can be limited by mitogen- and stress-activated protein kinases (MSK) 1 and 2, which are activated in the mitogen-activated protein kinase (MAPK) cascade. ${ }^{59}$ A cellular environment devoid of MSK1 and MSK2 hinders the binding of the phosphorylated transcription factors cAMP-responsive element-binding protein and activating transcription factor 1 to their cognate promoters. The binding of these transcription factors to their cognate promoters activates the antiinflammatory cytokine IL-10 and the MAPK phosphatase dual specificity phosphatase 1, which promotes p38 deactivation after LPS stimulation. MSK1- and MSK2knockout mice undergo a hyper-responsive state upon LPS treatment, resulting in endotoxin shock and inflammation for an extended time in an animal model. ${ }^{59}$ In a recent study, it was found that $\mathrm{p} 38 \gamma$ and $\mathrm{p} 38 \delta$, family members of $\mathrm{p} 38$ MAPKs, also regulate TLR4-mediated inflammation. Mice lacking $\mathrm{p} 38 \gamma$ and $\mathrm{p} 38 \delta$ showed abnormal responses when treated with LPS. This observation was attributed to the steady-state level of tumor progression locus 2, the MKK kinase that mediates ERK1/2 activation after TLR4 stimulation in the cell, maintained by p38 kinases. ${ }^{60}$ In addition, p38 $\gamma$ and p38 $\delta$ kinase deficiency rendered the mice hyporesponsive to LPS-induced septic shock.

In a recent study, it was observed that, in addition to propagating proinflammatory signals, NF- $\kappa$ B1 p50/p105 also regulates the secretion of IFN- $\beta$. Mice deficient in p50 secreted 
markedly higher amounts of IFN- $\beta$ and were associated with enhanced STAT1 phosphorylation, thus providing evidence that p50 is involved in inhibiting the IFN- $\beta$ response in normal cellular settings. This inhibitory effect is mediated by the tumor progression locus 2/ERK pathway. The ankyrin repeats of p50 stabilize tumor progression locus 2, an MAP3K, leading to poor secretion of IFN- $\beta$ in macrophages. ${ }^{61}$ Several signaling pathways require the activation of MAPK and NF- $\kappa B$ by TAK1. A positive regulatory role of TAK1 for NF- $\kappa B$ and MAPK has been reported earlier, ${ }^{62}$ whereas TAK1 is also considered to phosphorylate $\mathrm{p} 38$ and trigger the production of cytokines and reactive oxygen species induced by LPS. Mice with TAK1 deficiency in myeloid lineage cells are prone to lymphadenopathy and splenomegaly and are inclined to LPSinduced septic shock. These conditions are prevented by ablation of p38, pointing to the negative role of TAK1 in p38 activation.

Src homology 2 domain-containing protein tyrosine phosphatase (SHP)-1 and SHP-2 are likely to be involved in the regulation of proinflammatory signaling because SHP-1deficient mice rapidly develop inflammation-induced lesions in the MyD88-dependent pathway. ${ }^{63}$ IRAK1 and IRAK2 activities are suppressed by SHP-1, leading to a switch in the production of proinflammatory cytokines such as type I IFNs. This observation is consistent with a study that showed that IRAK1 is indispensable for the activation of NF- $\kappa B$ and the inhibition of type I IFN. In contrast to SHP-1, SHP-2 suppresses TRIF-dependent type I IFN production. ${ }^{64}$ Although SHP-2 catalyzes the phosphorylation of TANK-binding kinase1 , the phosphatase activity of SHP-2 is not required for TANKbinding kinase-1-activated gene expression. Thus, SHP-2 acts as an antagonist rather than as a phosphatase for TANKbinding kinase-1. In another study, a novel function of major histocompatibility complex I was elucidated. In parallel with TLR stimulation, Src kinase phosphorylates the intracellular domain of major histocompatibility complex I rendering this molecule accessible to Fps, a kinase with an Src homology domain. Fps then phosphorylates the SHP-2 molecule, leading to reduced TRAF6 activity. ${ }^{65}$

\section{Receptor cross-talk}

Under typical cellular conditions, receptors cross-communicate with each other to maintain normal physiological conditions. For example, mice with glucocorticoid receptor deficiency are severely affected when challenged with LPS. When this effect was studied, it was found that glucocorticoid receptor inhibited p38 MAPK but not PI3K/Akt, ERK, and c-Jun N-terminal kinase (in macrophages with functional glucocorticoid receptor) and hampered the immune response during TLR4 stimulation. ${ }^{66}$ Peroxisome proliferator-activated receptor- $\gamma$ has been implicated in the downregulation of IFN- $\beta$ production in response to TLR3 and 4 activation. It was observed that when peroxisome proliferator-activated receptor- $\gamma$ is induced by troglitazone, it results in impaired binding of IRF-3 to the IFN- $\beta$ promoter. Mice treated with troglitazone before LPS and poly(I:C) challenge secreted reduced levels of IFN- $\beta$, suggesting that peroxisome proliferator-activated receptor- $\gamma$ is involved in regulation of the TLR3 and 4 signaling pathways. ${ }^{67}$ In another study, a major hyaluronan receptor, $\mathrm{CD} 44$, was found to regulate the immune responses mediated by TLR2. CD44 is widely distributed in different tissues and alerts cells to injury. It has been demonstrated that CD44 also hinders the inflammatory response through its cytoplasmic domain, indicating a critical role for it in the regulation of TLR signaling. Mice with CD44 deficiency showed enhanced secretion of inflammatory mediators. ${ }^{68} \mathrm{CD} 300 \mathrm{a}$ and CD300f, members of the CD300 family, have been proven to reduce the expression of inflammatory cytokines in response to TLR4 and TLR9 activation while blocking cell activation through all TLRs in an SHP-dependent manner. By performing different experiments, it was concluded that SHP-1 could be activated either by CD300a or CD300f, leading to the inhibition of TLR9/MyD88-dependent signaling. ${ }^{69}$ TRIF-mediated signaling regulation requires both SHP-1 and SHP-2, which could be achieved only by CD300f. These studies showed differential regulation of the MyD88 and TRIF pathways by different CD300 family members.

In the regulation of immune responses, immunoreceptor tyrosine-based activation-motif-coupled receptors have an important role through interactions with other receptors such as TLRs. ${ }^{70} \beta_{2}$-Integrin and $\mathrm{Fc} \gamma \mathrm{R}$ cause the upregulation of IL-10 by $\mathrm{Ca}^{2}+$ signaling, culminating in a reduced innate immune response, thereby providing an indirect way to block TLR signaling. ${ }^{71}$ Moreover, CD11b activates splenic tyrosine kinase, which phosphorylates MyD88 and TRIF and facilitates their ubiquitin-mediated degradation. ${ }^{71}$ In contrast, CD11b positively controls the recruitment of MAL to the plasma membrane through phosphatidylinositol 4,5-bisphosphate and activation of cell surface-localizing TLRs, ${ }^{72}$ thus demonstrating a dual role of the integrin in TLR signaling. The adenosine 2A receptor has been reported to be involved in several inflammatory processes. In normal settings, this receptor is induced by the nucleoside adenosine and has been found to reduce inflammation by TLR4 and CD44. It was observed that adenosine $2 \mathrm{~A}$ receptor induction reduced the levels of inflammatory mediators, such as TNF- $\alpha$, IL-6, matrix metalloproteinase 13 (MMP13), and inducible nitric oxide synthase produced by IL-1 $\beta .^{73}$ These results implicated that adenosine $2 \mathrm{~A}$ receptor negatively affects IL- $1 \beta$-mediated proinflammation. Further studies are required to delineate the mechanistic details.

The complement system is another important branch of innate immunity that works to fight a microbial threat. In a recent study, a novel link between the complement system and its potential regulation of the immune response was explored. Activated TLRs on mouse macrophages produce IL-12 and IL-10 by their respective ligands. TLR-induced IL-12 production decreases, while IL-10 production increases by concurrent stimulation with complement fragment $\mathrm{C}_{5} \mathrm{a} .{ }^{74}$ This effect is PI3K independent, as opposed to results from earlier studies; however, this may depend on G-protein-mediated activation 
of ERK1/2, as this inhibitory effect is sensitive to treatment with pertussis toxin and PD98059.

\section{Feedback inhibition of TLR signaling}

Feedback inhibition contributes significantly to the overall regulation of TLR signaling. Several researchers have reported that various downstream proteins are induced and negatively regulate TLR signaling in response to TLR stimulation. Different studies with TRIM30 $\alpha$, a member of the tripartitemotif-containing (TRIM) protein superfamily, proved that this protein acts as an inhibitor of TLR signaling. TLR also induces the expression of TRIM $30 \alpha$, enhancing the degradation of TAK1-binding protein 2 (TAB2) and TAB3 from the TAB2-TAB3-TAK1 complex. ${ }^{75}$ Decreased availability of TABs shows reduced NF- $\mathrm{KB}$ activation and cytokine production. In support of these observations, findings related to TRIM $30 \alpha$ transgenic mice and in vivo knockdown studies have proven the protective effects of TRIM30 $\alpha$ during LPS-induced endotoxin shock. Another closely related protein that is induced by TLR activation, TRIM38, has an inhibitory effect on TLR signaling by promoting the K46-dependent polyubiquitination of TRAF6 and TRIF. $^{76,77}$ In addition, cylindromatosis, a tumor suppressor deubiquitination protein, has been reported to modulate TLR2 signaling. ${ }^{78}$ When TLR2 is activated, it also induces the expression of cylindromatosis, mediating the removal of polyubiquitin chains from TRAF6 and TRAF7, both of which are indispensable for NF- $\mathrm{KB}$ and MAPK activation by TLR2 ligands.

TLRs also induce the expression of certain negative

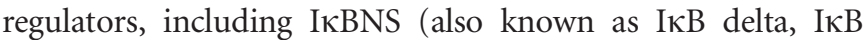
protein, and inhibitor of kappa light polypeptide gene enhancer in B cells) and B-cell CLL/lymphoma 3 (Bcl3). IкBNS lowers the effect of induction of IL- 6 and IL-12p40 without affecting TNF- $\alpha$ transcription. ${ }^{79}$ The mechanism underlying this phenomenon is that IкBNS binds to the IL-6 promoter but not to the TNF- $\alpha$ promoter. A knockout mouse model is more prone to develop endotoxin shock and intestinal inflammation, indicating an important role of IкBNS in inflammation. Bcl3, another member of the IкB family, is also important for TLR tolerance. ${ }^{80,81} \mathrm{Bcl} 3$ causes insensitivity in response to prolonged TLR stimulation, whereas Bcl3-deficient macrophages and DCs produce larger amounts of cytokines than normal cells. This observation suggests that $\mathrm{Bcl} 3$ limits the proinflammatory response by stabilizing the p50 subunit that occupies an NF- $\mathrm{kB}$ DNAbinding site.

\section{Autophagy}

In addition to the ubiquitin/proteasome system, autophagy also controls TLR signaling. ${ }^{82}$ Knockout of an autophagyrelated 16-like 1 caused the production of high levels of reactive oxygen species, IL-1 $\beta$, and IL-18 (TRIF-induced molecules) induced by LPS. $^{83}$ This study suggests that autophagy-related 16-like 1 suppresses the TRIF-dependent pathway, thereby leading to caspase-1 activation. Moreover, autophagy-related 16-like 1-deficient Paneth cells show increased expression of the genes involved in intestinal injury responses. ${ }^{84}$ The recently discovered autophagy protein, nuclear dot protein 52, exerts a negative effect on TLR3 signaling by disrupting TRIF and TRAF6 molecules in the absence of the A20 protein. TRAF6-dependent polyubiquitination of nuclear dot protein 52 occurs subsequent to TLR3 stimulation, leading to the aggregation and selective degradation of TRAF6. This protein selectively degrades the TRIF and TRAF6 molecules that are indispensable for TLRmediated signaling. ${ }^{85}$ Surprisingly, nuclear dot protein 52 could effectively suppress poly(I:C)-induced inflammatory gene expression during A20 silencing. In another study, it was reported that lysosome-associated small GTPase (also known as Rab7b) is involved in the lysosomal degradation of TLR4 subsequent to LPS stimulation, ${ }^{10}$ thereby corresponding to negative regulation of TLR-mediated inflammation.

\section{Transcriptional regulation}

Recent advances in molecular genetics and methodological refinements have unveiled new aspects of transcriptional regulation, such as chromatin remodeling, in different cell processes and inflammatory responses. ${ }^{86}$ In a recent study, it was reported that NF- $\mathrm{KB}$ has a pivotal role in TLR tolerance for preventing fatal consequences. It has been observed that NF- $\kappa B$-binding nucleic acids of gene promoters are tolerogenic motifs that recruit a repressor complex, comprising nuclear receptor corepressor-histone deacetylase 3-deacetylated-p50, to the inflammatory genes that shut down the transcription of inflammatory genes, while sparing the antimicrobial genes. ${ }^{87}$ The tolerizable genes convert to non-tolerizable genes when their motifs are mutated, whereas the opposite occurs when $\mathrm{NF}-\kappa \mathrm{B}$ motifs are inserted into non-tolerizable genes. During the generation of tolerance, repressosome assembly is based on NF- $\mathrm{kB}$ p50; however, this tolerance can be completely overcome by disrupting nuclear receptor corepressor-histone deacetylase 3 interaction with tolerogenic motifs. ATF3 facilitates the deacetylation of the promoter region of proinflammatory genes, recruiting histone deacetylase 1 and rendering this region difficult to access by transcription factors. ${ }^{88}$ ATF3-deficient macrophages secrete increased amounts of IL-12p40, IL-6, and TNF- $\alpha$ when treated with LPS.

Nuclear receptors also participate in immune response control by monitoring gene expression. Nuclear receptor related 1 protein forms a complex with p65 when the cell encounters LPS. This complex recruits the corepressor for RE1 silencing transcription factor (CoREST) complex, resulting in transcriptional repression of various genes. ${ }^{89}$ Microglia are myeloid cells from the central nervous system that respond to infection and tissue injury. Nuclear receptor related 1 proteindeficient microglia show hyper-responsiveness to stimuli, indicating a protective role of nuclear receptor related 1 protein. The aryl hydrocarbon receptor is present in the cytosol, senses the presence of chemical compounds, and has an important role in triggering the immune response. ${ }^{90}$ In 
macrophages, these receptors are stimulated by LPS and interact with STAT1 and NF- $\kappa \mathrm{B}$ in the IL-6 promoter, hindering IL-6 production. $^{91}$ The stability of RNA, mediated by $\mathrm{CCCH}$-type zinc-finger RNases, is also a major factor in controlling the transcription of inflammatory genes. Tristetraprolin mediates the deadenylation of TNF- $\alpha$ mRNA by binding to the $3^{\prime}$-untranslated region through deadenylase recruitment, leading to the disruption of mRNA. ${ }^{92}$ Aided by the RNase MCP-induced protein 1, tristetraprolin degrades IL-6 and IL-12p40 mRNA, and ameliorates the immune response towards various TLR ligands, thus protecting the animal from autoimmunity. ${ }^{93}$ Another study reported that inhibitor of $\kappa \mathrm{B}$ kinases also phosphorylate MCP-induced protein 1, which subsequently leads to proteasomal degradation, resulting in prevention of the inhibition of IL-6. ${ }^{94}$ Furthermore, MCP-induced protein 1 also degrades IL-2 mRNA through an AU-rich element-independent pathway, thereby modulating the immune response. ${ }^{95}$

\section{MicroRNA-mediated TLR signaling regulation}

In recent years, the importance of non-coding RNAs in gene regulation has been recognized. Several non-coding RNAs, including microRNA (miRNA), have been identified. miRNAs are induced by TLRs and have an important role in precisely controlling the response. ${ }^{96}$ These miRNAs often have several targets and bidirectional function, similar to miR-155. miR155 is a TLR-dependent miRNA ${ }^{97}$ with a dual physiological role in immune responses. ${ }^{98-105}$ miR-155 disintegrates MyD88, TAB2, and inducible inhibitor of $\kappa \mathrm{B}$ kinase mRNA to suppress TLR signaling, ${ }^{98-102}$ while targeting SHP- ${ }^{105}$ and enhancing signaling. MiR-146a is induced in response to LPS and downregulates the expression of TRAF6 and IRAK1 mRNA. ${ }^{106}$ MiR-146a-deficient mice develop myeloid sarcomas and chronic myeloproliferation due to the regulatory imbalance of NF- $\kappa B^{107}$ It has also been reported that, soon after birth, miR-146a is expressed at high levels in intestinal epithelial cells to protect the gut mucosa from bacteriainduced damage. ${ }^{108}$

Calcium/calmodulin-dependent protein kinase II $\alpha$, a crucial player in $\mathrm{Ca}^{2}+$ signaling, has been found to regulate the TLRtriggered inflammatory mediators and type I IFNs. The destabilization of calcium/calmodulin-dependent protein kinase II mRNA in DCs is regulated by the different family members of miR-148 (miR-148a, miR-148b, and miR-152). ${ }^{109}$ During DC maturation and TLR activation, increased levels of miRNAs are induced, which degrade calcium/calmodulindependent protein kinase II $\alpha$, thus limiting the secretion of inflammatory mediators and antigen production. Therefore, miRNA-148/152 influence immune responses that contribute to immune homeostasis. Programmed cell death protein 4 exerts proinflammatory effects by upregulating NF- $\mathrm{B}$ activity and IL-10 suppression. Programmed cell death protein 4 is crucial for the regulation of LPS responses. ${ }^{110} \mathrm{miR}-21$ is induced by LPS stimulation and negatively regulates inflammatory responses by decreasing programmed cell death protein 4 expression levels. Unlike other mechanisms of TLR inhibition, transcriptional regulation often enables control of a particular subset of TLR target genes without terminating TLR signaling. This property possibly contributes to the regulation of immune balance beyond the suppression of TLR signaling.

\section{Synthetic inhibitors}

Synthetic inhibitors have a potent role in the downregulation of inflammatory responses in several autoimmune diseases. Therefore, synthetic inhibitors are crucial in the negative regulation of TLRs. As the importance of synthetic inhibitors has been unveiled, several compounds are being used in different clinical trials and therapies (Table 2) for the treatment

Table 2 TLR antagonists and their associated targets and diseases

\begin{tabular}{lll}
\hline Inhibitor & Target molecule & Disease \\
\hline OxPAPC & CD14, MD-2, LBP & Sepsis \\
Chloroquine/hydroxychloroquine & TLR3, TLR7, TLR9 & SLE \\
Imidazoquinolines & TLR3, TLR9 & Autoimmune disease \\
Propidium iodide & TLR3, TLR7, TLR9 & Autoimmune disease \\
EM77/110 & MyD88/TIR domain interaction blockade & Inflammatory disease \\
ST2825 & Block MyD88 dimerization and interact with IRAK1 and IRAK4 & Chronic inflammatory disease \\
IM0-3100 & TLR7, TLR9 & Autoimmune disease \\
IRS-954 & TLR9 & Autoimmunity, SLE \\
E6446 & TLR9 & Inflammatory disease \\
Eritoran & TLR4 & Septic shock \\
DV1179 & TLR7, TLR9 & SLE \\
IPH-32XX & TLR7 & Autoimmune, cancer \\
E567 & TLR2, TLR4 & Anti-viral response
\end{tabular}

Abbreviations: CD14, cluster of differentiation 14. IRAK, IL-1 receptor-associated kinase. LBP, lipopolysaccharide-binding protein; MD-2, myeloid differentiation factor 2; MyD88, myeloid differentiation 88; OxPAPC, oxidized 1-palmitoyl-2-arachidonyl-sn-glycero-3-phosphorylcholine; TIR, Toll/interleukin-1 receptor; TLR, Toll-like receptors. 
of diseases. Several antimalarial drugs have been used in the treatment of SLE, including chloroquine, hydroxychloroquine, and quinacrine. These compounds prevent the acidification of endosomes that hinders the activation of endosomal TLRs. Besides these compounds, imidazoquinolines prevent the activation of TLR3 and TLR9, possibly by masking the TLR binding epitope of the nucleic acids. Propidium iodide binds to nucleic acids in the endosomes and prevents the activation of endosomal TLRs. ${ }^{111}$ Furthermore, immunoregulatory DNA sequences are oligonucleotides that, instead of activating TLRs, are engaged in TLR9 signaling inhibition. These molecules alleviate the proinflammatory response caused by $\mathrm{CpG}$ stimulation and can be therapeutically beneficial. These immunoregulatory DNA sequences have been found to be equally potent in both mice and humans. ${ }^{112}$

A previous study showed that oxidized phospholipids, such as oxidized 1-palmitoyl-2-arachidonyl-sn-glycero-3-phosphorylcholine (OxPAPC), can block the signaling induced by bacterial lipopeptide or LPS through TLR2 and TLR4 by manipulating CD14, LPS-binding protein, and MD-2 in the serum. The presence of OxPAPC reduces the expression of TNF- $\alpha$, IL- 6 , and IL-12, while this blockade can be reversed by providing CD14 and LPS-binding proteins in excess to the serum. ${ }^{113}$ In an effort to discover new compounds, a study was performed to identify an inhibitor of TLR2-mediated inflammation. Of the 101306 compounds screened, E567 was effective in reducing viral replication in the cell. ${ }^{114}$ E567 could modulate TLR2 signaling, and to a lesser extent TLR4, and could provide an alternative antiviral therapeutic option. MyD88 in TLR signaling represents an attractive therapeutic target. Through chemical screening, different compounds that mimic the $\mathrm{BB}$ loop structure of MyD88 have been discovered. For example, EM77 and EM110 presumably interrupt the association between IL-1R and MyD88, ${ }^{115}$ and ST2825 inhibits MyD88 homodimerization. ${ }^{116}$ These compounds have opened new avenues for the attenuation of TLR signaling, in addition to the options available for the direct antagonism of TLRs.

\section{RECENT ADVANCES IN THE NEGATIVE REGULATION OF TLRS}

The findings of a recent study that elucidated the negative roles of $14-3-3 \varepsilon$ and $14-3-3 \sigma$ in TLR2-, TLR3-, TLR4-, TLR7/8-, and TLR9-dependent proinflammation and type I IFN production helped expand the group of negative regulators of TLRs. It has been reported that these proteins interact with MyD88, MAL, TRIF, and TRAM, as well as TRAF3 and TRAF6, and influence the production of regulated and normal $\mathrm{T}$ cell expressed and secreted, after being phosphorylated, in the case of all TLRs, except TLR3. Further studies are required to define the role of these proteins in TLR signaling. ${ }^{117} \mathrm{miR}$ 223 has been shown to affect negatively TLR signaling by downregulating STAT3 in murine macrophage cell lines and in primary macrophages. IL-6 production following TLR activation leads to the downregulation of miR-233, resulting in the profound expression of STAT3. The forced expression of miR-233 is accompanied by a decrease in STAT3 and reduced production of IL- 6 and IL-1 $\beta$, thus confirming the negative role of miR-233. ${ }^{118}$ MMPs have versatile roles in cellular physiology, including infiltration and immune response regulation. Recently, MMP-8 was reported to have a protective role through the cleavage of the inflammatory mediators S100A8 and S100A9. MMP8 deficiency was found to worsen lung inflammation in an endotoxemia model. ${ }^{119}$ This study provided a new role for these MMPs, but due to multiple contradictory functions, it is necessary to further explore the precise mechanism underlying the effect of these proteins. Triggering receptor expressed on myeloid cell 2 is another receptor that regulates the TLR-mediated inflammatory response by employing immunoreceptor tyrosine-based activation-motif-containing adaptor molecules, such as DNAX-activation protein 12 and $\mathrm{FcR} \gamma$, in bone marrow-derived dendritic cells. ${ }^{120}$ The mouse model with triggering receptor expressed on myeloid cell 2 deficiency showed exaggerated cytokine production and a type I IFN response, thus suggesting a negative role for this receptor. NOD-like receptors (NLRs) activate the immune system as well as modulate the TLR-mediated immune system. NLRC3 (NOD-like receptor family CARD domain containing 3), one of the NLRs, modulates TLR-induced NF- $\mathrm{KB}$ activation by hindering ubiquitin-mediated TRAF6 activation. When cells are treated with LPS, the level of NLRC3 mRNA reduces, while mice lacking NLRC3 secrete increased levels of proinflammatory mediators, suggesting a negative role for NLRC3 in TLR signaling, possibly through the formation of a TRAFasome complex. ${ }^{121}$

\section{CONCLUSIONS AND FUTURE PROSPECTS}

The vital role of TLRs against invading microorganisms has been appreciated since it was first discovered that TLR4 detects LPS. Since then, several studies have been performed to elucidate TLR-mediated inflammatory pathways. ${ }^{122}$ These studies have unveiled the role of TLRs in inflammation as well as the undesired roles of TLRs in several inflammatory diseases. Overactivation of TLRs disrupts homeostasis and places the patient at an increased risk of developing autoimmune diseases. To control hyper-responses, cells have evolved different mechanisms to protect the host, involving a plethora of molecules. At different stages, different molecules prevent the excessive secretion of inflammatory mediators and assist the immune system in restoring homeostasis. In the absence of these regulatory molecules, fatal consequences are inevitable (Figure 3).

TLRs are regulated at the genetic, transcriptional, translational, and post-translational levels by a combination of molecules. As an increasing number of studies are being performed, new regulators will be discovered, highlighting the importance of TLR regulation. These regulatory molecules also provide opportunities to exploit and design new therapies that facilitate the treatment of inflammatory diseases. 


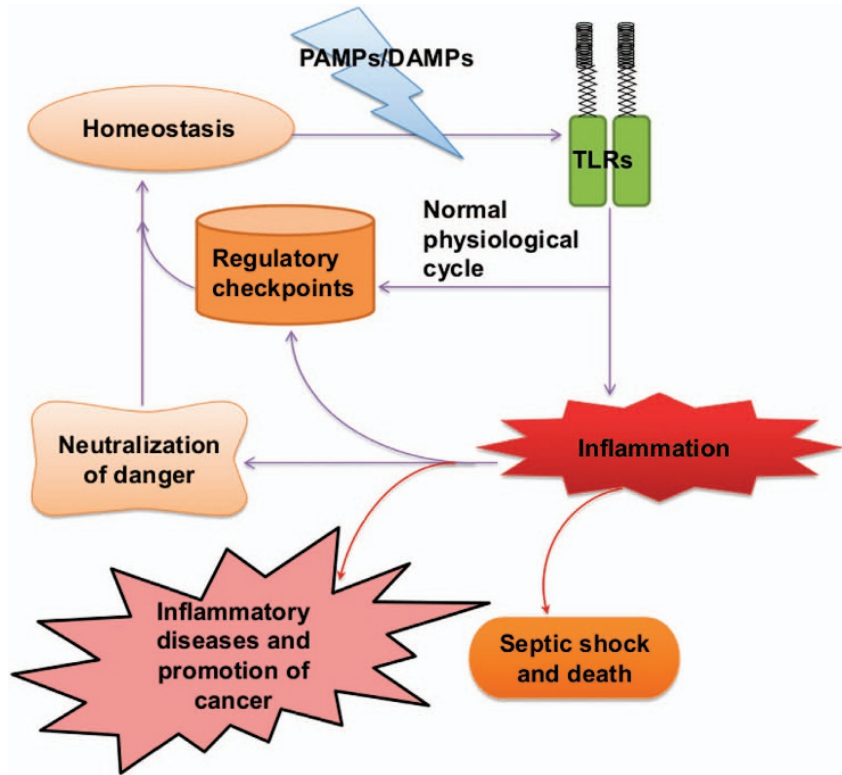

Figure 3 Model of the Toll-like receptor (TLR)-dependent pro- and anti-inflammatory balance. During homeostasis, when pathogen/ damage-associated molecular patterns (PAMPs/DAMPs) breach the protective barrier, TLRs sense these patterns and mount an inflammatory response. As part of the inflammatory response, TLRs activate negative regulators, which have also shown to be triggered by inflammatory cytokines. The inflammatory response neutralizes the danger, and negative regulators prevent the overactivation of the immune system to protect the host. In the case of lack of appropriate TLR stimulation, the propagation of signals, or the induction of an inflammatory mediator, bacteremia may occur, whereas overactivation of any component leads to the development of inflammatory diseases and septic shock.

Moreover, by devising strategies to stabilize negative regulatory molecules, it is possible to alleviate the severity of autoimmune diseases. Furthermore, other signaling pathways of the innate immune system also influence the negative regulation of TLR signaling. The regulators are differentially activated in a context-dependent and cell-specific manner, leading to complex interactions. Additional studies are required to characterize the regulation in this system via these interactions. These future studies will provide new directions for the therapeutic targeting of several microbial infections and immune disorders.

\section{CONFLICT OF INTEREST}

The authors declare no conflict of interest.

\section{ACKNOWLEDGEMENTS}

This work was supported by the Mid-Career Researcher Program through the National Research Foundation of Korea, funded by the Ministry of Education, Science and Technology (2012-016803). This work was also partly supported by a grant from the Priority Research Centers Program (NRF 2012-0006687).
1 Lemaitre B, Nicolas E, Michaut L, Reichhart JM, Hoffmann JA. The dorsoventral regulatory gene cassette spatzle/Toll/cactus controls the potent antifungal response in Drosophila adults. Cell 1996; 86: 973-983.

2 Medzhitov R, Preston-Hurlburt P, Janeway CA. A human homologue of the Drosophila Toll protein signals activation of adaptive immunity. Nature 1997; 388: 394-397.

3 Poltorak A, He X, Smirnova I, Liu MY, Van Huffel C, Du X et al. Defective LPS signaling in $\mathrm{C} 3 \mathrm{H} / \mathrm{HeJ}$ and $\mathrm{C} 57 \mathrm{BL} / 10 \mathrm{ScCr}$ mice: mutations in TIr4 gene. Science 1998; 282: 2085-2088.

4 Qureshi ST, Larivière L, Leveque G, Clermont S, Moore KJ, Gros P et al. Endotoxin-tolerant mice have mutations in Toll-like receptor 4 (TIr4). J Exp Med 1999; 189: 615-625.

5 Hoshino K, Takeuchi O, Kawai T, Sanjo H, Ogawa T, Takeda $Y$ et al. Cutting Edge: toll-like receptor 4 (TLR4)-deficient mice are hyporesponsive to lipopolysaccharide: evidence for TLR4 as the Lps gene product. J Immunol 1999; 162: 3749-3752.

6 Oldenburg M, Kruger A, Ferstl R, Kaufmann A, Nees G, Sigmund A et al. TLR13 recognizes bacterial 23 S rRNA devoid of erythromycin resistanceforming modification. Science 2012; 337: 1111-1115.

7 Kawai T, Akira S. TLR signaling. Semin Immunol 2007; 19: 24-32.

8 Latz E, Schoenemeyer A, Visintin A, Fitzgerald KA, Monks BG, Knetter CF et al. TLR9 signals after translocating from the ER to CpG DNA in the Iysosome. Nat Immunol 2004; 5: 190-198.

9 Underhill DM, Ozinsky A, Hajjar AM, Stevens A, Wilson CB, Bassetti M et al. The Toll-like receptor 2 is recruited to macrophage phagosomes and discriminates between pathogens. Nature 1999; 401: 811-815.

10 Wang Y, Chen T, Han C, He D, Liu H, An H et al. Lysosome-associated small Rab GTPase Rab7b negatively regulates TLR4 signaling in macrophages by promoting lysosomal degradation of TLR4. Blood 2007; 110: 962-971

11 Medzhitov R. Toll-like receptors and innate immunity. Nat Rev Immunol 2001; 1: 135-145.

12 Pasare C, Medzhitov R. Control of B-cell responses by Toll-like receptors. Nature 2005; 438: 364-368.

13 Zasloff M. Antimicrobial peptides of multicellular organisms. Nature 2002; 415: 389-395.

14 Doyle SE, O'Connell RM, Miranda GA, Vaidya SA, Chow EK, Liu PT et al. Toll-like receptors induce a phagocytic gene program through p38. J Exp Med 2004; 199: 81-90.

15 Werling D, Hope JC, Howard CJ, Jungi TW. Differential production of cytokines, reactive oxygen and nitrogen by bovine macrophages and dendritic cells stimulated with Toll-like receptor agonists. Immunology 2004; 111: 41-52.

16 Nijhuis MM, Pasterkamp G, Sluis NI, de Kleijn DP, Laman JD, Ulfman LH. Peptidoglycan increases firm adhesion of monocytes under flow conditions and primes monocyte chemotaxis. J Vasc Res 2007; 44: 214-222.

17 Kaisho T, Akira S. Toll-like receptor function and signaling. J Allergy Clin Immunol 2006; 117: 979-987; quiz 988.

18 Salaun B, Romero P, Lebecque S. Toll-like receptors' two-edged sword: when immunity meets apoptosis. Eur J Immunol 2007; 37: 3311-3318.

19 Iwasaki A, Medzhitov R. Toll-like receptor control of the adaptive immune responses. Nat Immunol 2004; 5: 987-995.

20 Pasare C, Medzhitov R. Toll-like receptors: linking innate and adaptive immunity. Adv Exp Med Biol 2005; 560: 11-18.

21 Palm NW, Medzhitov R. Pattern recognition receptors and control of adaptive immunity. Immunol Rev 2009; 227: 221-233.

22 Li M, Zhou Y, Feng G, Su SB. The critical role of Toll-like receptor signaling pathways in the induction and progression of autoimmune diseases. Curr Mol Med 2009; 9: 365-374.

23 Basith S, Manavalan B, Yoo TH, Kim SG, Choi S. Roles of toll-like receptors in cancer: a double-edged sword for defense and offense. Arch Pharm Res 2012; 35: 1297-1316.

24 Viglianti GA, Lau CM, Hanley TM, Miko BA, Shlomchik MJ, MarshakRothstein A. Activation of autoreactive B cells by $\mathrm{CpG}$ dsDNA. Immunity 2003; 19: 837-847.

25 Brentano F, Schorr O, Gay RE, Gay S, Kyburz D. RNA released from necrotic synovial fluid cells activates rheumatoid arthritis synovial fibroblasts via toll-like receptor 3. Arthritis Rheumat 2005; 52: 2656-2665.

26 LeBouder E, Rey-Nores JE, Rushmere NK, Grigorov M, Lawn SD, Affolter $\mathrm{M}$ et al. Soluble forms of Toll-like receptor (TLR)2 capable of modulating 
tIr2 signaling are present in human plasma and breast milk. J Immunol 2003; 171: 6680-6689.

27 LeBouder E, Rey-Nores JE, Rushmere NK, Grigorov M, Lawn SD, Affolter $M$ et al. Soluble forms of Toll-like receptor (TLR)2 capable of modulating TLR2 signaling are present in human plasma and breast milk. J Immunol 2003; 171: 6680-6689.

28 Iwami KI, Matsuguchi T, Masuda A, Kikuchi T, Musikacharoen T, Yoshikai Y. Cutting edge: naturally occurring soluble form of mouse Toll-like receptor 4 inhibits lipopolysaccharide signaling. J Immunol 2000; 165: 6682-6686.

29 Kitchens RL, Thompson PA, Viriyakosol S, O'Keefe GE, Munford RS. Plasma CD14 decreases monocyte responses to LPS by transferring cellbound LPS to plasma lipoproteins. J Clin Invest 2001; 108: 485-493.

30 Sweet MJ, Leung BP, Kang D, Sogaard M, Schulz K, Trajkovic V et al. A novel pathway regulating lipopolysaccharide-induced shock by ST2/T1 via inhibition of Toll-like receptor 4 expression. J Immunol 2001; 166: 6633-6639.

31 Wald D, Qin J, Zhao Z, Qian Y, Naramura M, Tian L et al. SIGIRR, a negative regulator of Toll-like receptor-interleukin 1 receptor signaling. Nat Immunol 2003; 4: 920-927.

32 Brint EK, Xu D, Liu H, Dunne A, McKenzie AN, O'Neill LA et al. ST2 is an inhibitor of interleukin 1 receptor and Toll-like receptor 4 signaling and maintains endotoxin tolerance. Nat Immunol 2004; 5: 373-379.

33 Basith S, Manavalan B, Govindaraj RG, Choi S. In silico approach to inhibition of signaling pathways of Toll-like receptors 2 and 4 by ST2L. PLoS One 2011; 6: e23989.

34 Divanovic S, Trompette A, Atabani SF, Madan R, Golenbock DT, Visintin A et al. Negative regulation of Toll-like receptor 4 signaling by the Toll-like receptor homolog RP105. Nat Immunol 2005; 6: 571-578.

35 O'Neill LA, Bowie AG. The family of five: TIR-domain-containing adaptors in Toll-like receptor signalling. Nat Rev Immunol 2007; 7: 353-364.

36 Palsson-McDermott EM, Doyle SL, McGettrick AF, Hardy M, Husebye $H$, Banahan $\mathrm{K}$ et al. TAG, a splice variant of the adaptor TRAM, negatively regulates the adaptor MyD88-independent TLR4 pathway. Nat Immunol 2009; 10: 579-586.

37 Doyle SL, Husebye H, Connolly DJ, Espevik T, O'Neill LA, McGettrick AF. The GOLD domain-containing protein TMED7 inhibits TLR4 signalling from the endosome upon LPS stimulation. Nat Commun 2012; 3: 707.

38 Wang T, Chuang TH, Ronni T, Gu S, Du YC, Cai H et al. Flightless I homolog negatively modulates the TLR pathway. J Immunol 2006; 176: 1355-1362.

39 Carty M, Goodbody R, Schroder M, Stack J, Moynagh PN, Bowie AG. The human adaptor SARM negatively regulates adaptor protein TRIFdependent Toll-like receptor signaling. Nat Immunol 2006; 7: 1074-1081.

40 Siednienko J, Halle A, Nagpal K, Golenbock DT, Miggin SM. TLR3-mediated IFN-beta gene induction is negatively regulated by the TLR adaptor MyD88 adaptor-like. Eur J Immunol 2010; 40: 3150-3160.

41 Seregin SS, Aldhamen YA, Appledorn DM, Aylsworth CF, Godbehere S, Liu CJ et al. TRIF is a critical negative regulator of TLR agonist mediated activation of dendritic cells in vivo. PLoS One 2011; 6: e22064.

42 Peng Q, O'Loughlin JL, Humphrey MB. DOK3 negatively regulates LPS responses and endotoxin tolerance. PLoS One 2012; 7: e39967.

43 Han C, Jin J, Xu S, Liu H, Li N, Cao X. Integrin CD11b negatively regulates TLR-triggered inflammatory responses by activating Syk and promoting degradation of MyD88 and TRIF via Cbl-b. Nat Immunol 2010; 11: 734-742.

44 Shimauchi H, Ogawa T, Okuda K, Kusumoto Y, Okada H. Autoregulatory effect of interleukin-10 on proinflammatory cytokine production by Porphyromonas gingivalis lipopolysaccharide-tolerant human monocytes. Infect Immun 1999; 67: 2153-2159.

45 Troutman TD, Hu W, Fulenchek S, Yamazaki T, Kurosaki T, Bazan JF et al. Role for B-cell adapter for PI3K (BCAP) as a signaling adapter linking Toll-like receptors (TLRs) to serine/threonine kinases PI3K/Akt. Proc Natl Acad Sci 2012; 109: 273-278.

46 Kawagoe T, Takeuchi O, Takabatake Y, Kato H, Isaka Y, Tsujimura T et al. TANK is a negative regulator of Toll-like receptor signaling and is critical for the prevention of autoimmune nephritis. Nat Immunol 2009; 10: 965-972.

47 Yuk JM, Shin DM, Lee HM, Kim JJ, Kim SW, Jin HS et al. The orphan nuclear receptor SHP acts as a negative regulator in inflammatory signaling triggered by Toll-like receptors. Nat Immunol 2011; 12: 742-751.
48 Yoshimura A, Naka T, Kubo M. SOCS proteins, cytokine signalling and immune regulation. Nat Rev Immunol 2007; 7: 454-465.

49 Kayagaki N, Phung Q, Chan S, Chaudhari R, Quan C, O'Rourke KM et al. A deubiquitinase that regulates type I interferon production. Science 2007; 318: 1628-1632.

50 Tanaka T, Grusby MJ, Kaisho T. PDLIM2-mediated termination of transcription factor NF-kappaB activation by intranuclear sequestration and degradation of the p65 subunit. Nat Immunol 2007; 8: 584-591.

51 Saitoh T, Tun-Kyi A, Ryo A, Yamamoto M, Finn G, Fujita T et al. Negative regulation of interferon-regulatory factor 3-dependent innate antiviral response by the prolyl isomerase Pin1. Nat Immunol 2006; 7: 598-605.

52 Tun-Kyi A, Finn G, Greenwood A, Nowak M, Lee TH, Asara JM et al. Essential role for the prolyl isomerase Pin 1 in Toll-like receptor signaling and type I interferon-mediated immunity. Nat Immunol 2011; 12: 733-741.

53 Yu Y, Hayward GS. The ubiquitin E3 ligase RAUL negatively regulates type I interferon through ubiquitination of the transcription factors IRF7 and IRF3. Immunity 2010; 33: 863-877.

54 Turer EE, Tavares RM, Mortier E, Hitotsumatsu O, Advincula R, Lee B et al. Homeostatic MyD88-dependent signals cause lethal inflammation in the absence of A20. J Exp Med 2008; 205: 451-464.

55 Skaug B, Chen J, Du F, He J, Ma A, Chen ZJ. Direct, noncatalytic mechanism of IKK inhibition by A20. Mol Cell 2011; 44: 559-571.

56 Zhou F, Zhang X, van Dam H, Ten Dijke P, Huang H, Zhang L. Ubiquitinspecific protease 4 mitigates Toll-like/interleukin-1 receptor signaling and regulates innate immune activation. J Biol Chem 2012; 287: $11002-11010$.

57 He X, Li Y, Li C, Liu LJ, Zhang XD, Liu Y et al. USP2a negatively regulates IL-1 beta- and virus-induced NF-kappaB activation by deubiquitinating TRAF6. J Mol Cell Biol 2012; e-pub ahead of print 19 May 2012; doi: $10.1093 / \mathrm{jmcb} / \mathrm{mjs} 024$.

58 Zhong B, Liu X, Wang X, Liu X, Chang SH, Li H et al. Regulation of TLRtriggered innate immune response by ubiquitin-specific protease $25 . \mathrm{J}$ Immunol 2012; 188: (Meeting Abstract Supplement) 180.8.

59 Ananieva O, Darragh J, Johansen C, Carr JM, Mcllrath J, Park JM et al. The kinases MSK1 and MSK2 act as negative regulators of Toll-like receptor signaling. Nat Immunol 2008; 9: 1028-1036.

60 Risco A, del Fresno C, Mambol A, Alsina-Beauchamp D, MacKenzie KF Yang HT et al. P38 $\gamma$ and p38 kinases regulate the Toll-like receptor 4 (TLR4)-induced cytokine production by controlling ERK1/2 protein kinase pathway activation. Proc Natl Acad Sci 2012; 109: 11200-11205.

61 Yang HT, Wang Y, Zhao X, Demissie E, Papoutsopoulou S, Mambole A et al. NF-kappaB1 inhibits TLR-induced IFN-beta production in macrophages through TPL-2-dependent ERK activation. J Immunol 2011; 186: 1989-1996.

62 Ajibade AA, Wang Q, Cui J, Zou J, Xia X, Wang M et al. TAK1 negatively regulates NF-kappaB and p38 MAP kinase activation in Gr-1 + CD11b + neutrophils. Immunity 2012; 36: 43-54.

63 An H, Hou J, Zhou J, Zhao W, Xu H, Zheng Y et al. Phosphatase SHP-1 promotes TLR- and RIG-I-activated production of type I interferon by inhibiting the kinase IRAK1. Nat Immunol 2008; 9: 542-550.

64 An H, Zhao W, Hou J, Zhang Y, Xie Y, Zheng Y et al. SHP-2 phosphatase negatively regulates the TRIF adaptor protein-dependent type I interferon and proinflammatory cytokine production. Immunity 2006; 25: 919-928.

65 Xu S, Liu X, Bao Y, Zhu X, Han C, Zhang P et al. Constitutive $\mathrm{MHC}$ class I molecules negatively regulate TLR-triggered inflammatory responses via the Fps-SHP-2 pathway. Nat Immunol 2012; 13: 551-559.

66 Bhattacharyya S, Brown DE, Brewer JA, Vogt SK, Muglia LJ. Macrophage glucocorticoid receptors regulate Toll-like receptor 4-mediated inflammatory responses by selective inhibition of p38 MAP kinase. Blood 2007; 109: 4313-4319.

67 Zhao W, Wang L, Zhang M, Wang P, Zhang L, Yuan C et al. Peroxisome proliferator-activated receptor gamma negatively regulates IFN-beta production in Toll-like receptor (TLR) 3- and TLR4-stimulated macrophages by preventing interferon regulatory factor 3 binding to the IFN-beta promoter. J Biol Chem 2011; 286: 5519-5528.

68 Kawana H, Karaki H, Higashi M, Miyazaki M, Hilberg F, Kitagawa M et al. CD44 suppresses TLR-mediated inflammation. J Immunol 2008; 180: 4235-4245. 
69 Lee SM, Kim EJ, Suk K, Lee WH. CD300F blocks both MyD88 and TRIFmediated TLR signaling through activation of Src homology region 2 domain-containing phosphatase 1. J Immunol 2011; 186: 6296-6303.

70 Ivashkiv LB. Cross-regulation of signaling by ITAM-associated receptors. Nat Immunol 2009; 10: 340-347.

71 Wang L, Gordon RA, Huynh L, Su X, Park Min KH, Han J et al. Indirect inhibition of Toll-like receptor and type I interferon responses by ITAM-coupled receptors and integrins. Immunity 2010; 32: 518-530.

72 Kagan JC, Medzhitov R. Phosphoinositide-mediated adaptor recruitment controls Toll-like receptor signaling. Cell 2006; 125: 943-955.

73 Campo GM, Avenoso A, D'Ascola A, Scuruchi M, Prestipino V, Nastasi G et al. Adenosine $\mathrm{A} 2 \mathrm{~A}$ receptor activation and hyaluronan fragment inhibition reduce inflammation in mouse articular chondrocytes stimulated with interleukin-1 beta. FEBS J 2012; 279: 2120-2133.

74 Okazaki N, Hazeki K, Izumi T, Nigorikawa K, Hazeki O. C5a controls TLRinduced IL-10 and IL-12 production independent of phosphoinositide 3kinase. J Biochem 2011; 149: 265-274.

75 Shi M, Deng W, Bi E, Mao K, Ji Y, Lin G et al. TRIM30 alpha negatively regulates TLR-mediated NF-kappa B activation by targeting TAB2 and TAB3 for degradation. Nat Immunol 2008; 9: 369-377.

76 Zhao W, Wang L, Zhang M, Yuan C, Gao C. E3 ubiquitin ligase tripartite motif 38 negatively regulates TLR-mediated immune responses by proteasomal degradation of TNF receptor-associated factor 6 in macrophages. J Immunol 2012; 188: 2567-2574.

77 Xue Q, Zhou Z, Lei X, Liu X, He B, Wang J et al. TRIM38 negatively regulates TLR3-mediated IFN- $\beta$ signaling by targeting TRIF for degradation. PLoS One 2012; 7: e46825.

78 Yoshida H, Jono H, Kai H, Li JD. The tumor suppressor cylindromatosis (CYLD) acts as a negative regulator for toll-like receptor 2 signaling via negative cross-talk with TRAF6 AND TRAF7. J Biol Chem 2005; 280: 41111-41121.

79 Kuwata H, Matsumoto M, Atarashi K, Morishita H, Hirotani T, Koga R et al. IkappaBNS inhibits induction of a subset of Toll-like receptor-dependent genes and limits inflammation. Immunity 2006; 24: 41-51.

80 Manavalan B, Basith S, Choi YM, Lee G, Choi S. Structure-function relationship of cytoplasmic and nuclear IkappaB proteins: an in silico analysis. PLoS One 2010; 5: e15782.

81 Carmody RJ, Ruan Q, Palmer S, Hilliard B, Chen YH. Negative regulation of toll-like receptor signaling by NF-kappaB p50 ubiquitination blockade. Science 2007: 317: 675-678.

82 Levine B, Mizushima N, Virgin HW. Autophagy in immunity and inflammation. Nature 2011; 469: 323-335.

83 Saitoh T, Fujita N, Jang MH, Uematsu S, Yang BG, Satoh T et al. Loss of the autophagy protein Atg16L1 enhances endotoxin-induced IL-1beta production. Nature 2008; 456: 264-268.

84 Cadwell K, Liu JY, Brown SL, Miyoshi H, Loh J, Lennerz JK et al. A key role for autophagy and the autophagy gene Atg16/1 in mouse and human intestinal Paneth cells. Nature 2008; 456: 259-263.

85 Inomata M, Niida S, Shibata K-i, Into T. Regulation of Toll-like receptor signaling by NDP52-mediated selective autophagy is normally inactivated by A20. Cell Mol Life Sci 2012; 69: 963-979.

86 Ramirez-Carrozzi VR, Nazarian AA, Li CC, Gore SL, Sridharan R, Imbalzano AN et al. Selective and antagonistic functions of SWI/SNF and $\mathrm{Mi}$-2beta nucleosome remodeling complexes during an inflammatory response. Genes Dev 2006; 20: 282-296.

87 Yan Q, Carmody RJ, Qu Z, Ruan Q, Jager J, Mullican SE et al. Nuclear factor-kappaB binding motifs specify Toll-like receptor-induced gene repression through an inducible repressosome. Proc Natl Acad Sci USA 2012; 109: 14140-14145.

88 Whitmore MM, Iparraguirre A, Kubelka L, Weninger W, Hai T, Williams BR. Negative regulation of TLR-signaling pathways by activating transcription factor-3. J Immunol 2007; 179: 3622-3630.

89 Saijo K, Winner B, Carson CT, Collier JG, Boyer L, Rosenfeld MG et al. A Nurr1/COREST pathway in microglia and astrocytes protects dopaminergic neurons from inflammation-induced death. Cell 2009; 137: 47-59.

90 Esser C, Rannug A, Stockinger B. The aryl hydrocarbon receptor in immunity. Trends Immunol 2009; 30: 447-454.

91 Kimura A, Naka T, Nakahama T, Chinen I, Masuda K, Nohara K et al. Aryl hydrocarbon receptor in combination with Stat1 regulates LPS-induced inflammatory responses. J Exp Med 2009; 206: 2027-2035.

92 Carrick DM, Lai WS, Blackshear PJ. The tandem CCCH zinc finger protein tristetraprolin and its relevance to cytokine mRNA turnover and arthritis. Arthritis Res Ther 2004; 6: 248-264.
93 Matsushita K, Takeuchi O, Standley DM, Kumagai Y, Kawagoe T, Miyake T et al. Zc3h12a is an RNase essential for controlling immune responses by regulating mRNA decay. Nature 2009; 458: 1185-1190.

94 Iwasaki H, Takeuchi O, Teraguchi S, Matsushita K, Uehata T, Kuniyoshi K et al. The IkappaB kinase complex regulates the stability of cytokineencoding mRNA induced by TLR-IL-1 R by controlling degradation of regnase-1. Nat Immunol 2011; 12: 1167-1175.

95 Li M, Cao W, Liu H, Zhang W, Liu X, Cai Z et al. MCPIP1 down-regulates IL-2 expression through an ARE-independent pathway. PLoS One 2012; 7: e49841.

96 O'Neill LA, Sheedy FJ, McCoy CE. MicroRNAs: the fine-tuners of Toll-like receptor signalling. Nat Rev Immunol 2011; 11: 163-175.

97 O'Connell RM, Taganov KD, Boldin MP, Cheng G, Baltimore D. MicroRNA-155 is induced during the macrophage inflammatory response. Proc Natl Acad Sci 2007; 104: 1604-1609.

98 Huang RS, Hu GQ, Lin B, Lin ZY, Sun CC. MicroRNA-155 silencing enhances inflammatory response and lipid uptake in oxidized low-density lipoprotein-stimulated human THP-1 macrophages. J Investig Med 2010; 58: 961-967.

99 Tang B, Xiao B, Liu Z, Li N, Zhu ED, Li BS et al. Identification of MyD88 as a novel target of miR-155, involved in negative regulation of Helicobacter pylori-induced inflammation. FEBS Lett 2010; 584: 1481-1486.

100 Ceppi M, Pereira PM, Dunand-Sauthier I, Barras E, Reith W, Santos MA et al. MicroRNA-155 modulates the interleukin-1 signaling pathway in activated human monocyte-derived dendritic cells. Proc Natl Acad Sci USA 2009; 106: 2735-2740.

101 Tili E, Michaille JJ, Cimino A, Costinean S, Dumitru CD, Adair B et al. Modulation of miR-155 and miR-125b levels following lipopolysaccharide/TNF-alpha stimulation and their possible roles in regulating the response to endotoxin shock. J Immunol 2007; 179: 5082-5089.

102 Gottwein E, Mukherjee N, Sachse C, Frenzel C, Majoros WH, Chi JT et al. A viral microRNA functions as an orthologue of cellular miR-155. Nature 2007; 450: 1096-1099.

103 Thai TH, Calado DP, Casola S, Ansel KM, Xiao C, Xue Y et al. Regulation of the germinal center response by microRNA-155. Science 2007; 316: 604-608.

104 Rodriguez A, Vigorito E, Clare S, Warren MV, Couttet P, Soond DR et al. Requirement of bic/microRNA-155 for normal immune function. Science 2007; 316: 608-611.

105 O'Connell RM, Chaudhuri AA, Rao DS, Baltimore D. Inositol phosphatase SHIP1 is a primary target of miR-155. Proc Natl Acad Sci 2009; 106: 7113-7118.

106 Taganov KD, Boldin MP, Chang KJ, Baltimore D. NF-kappaB-dependent induction of microRNA miR-146, an inhibitor targeted to signaling proteins of innate immune responses. Proc Natl Acad Sci USA 2006; 103: 12481-12486.

107 Zhao JL, Rao DS, Boldin MP, Taganov KD, O'Connell RM, Baltimore D. NF-kappaB dysregulation in microRNA-146a-deficient mice drives the development of myeloid malignancies. Proc Natl Acad Sci USA 2011; 108: 9184-9189.

108 Chassin C, Kocur M, Pott J, Duerr CU, Gutle D, Lotz M et al. miR-146a mediates protective innate immune tolerance in the neonate intestine. Cell Host Microbe 2010; 8: 358-368.

109 Liu X, Zhan Z, Xu L, Ma F, Li D, Guo Z et al. MicroRNA-148/152 impair innate response and antigen presentation of TLR-triggered dendritic cells by targeting CaMKIlalpha. J Immunol 2010; 185: 7244-7251.

110 Sheedy FJ, Palsson-McDermott E, Hennessy EJ, Martin C, O'Leary JJ, Ruan $Q$ et al. Negative regulation of TLR4 via targeting of the proinflammatory tumor suppressor PDCD4 by the microRNA miR-21. Nat Immunol 2010; 11: 141-147.

111 Kužnik A, Benčina M, Švajger U, Jeras M, Rozman B, Jerala R. Mechanism of endosomal TLR inhibition by antimalarial drugs and imidazoquinolines. J Immunol 2011; 186: 4794-4804.

112 Duramad O, Fearon KL, Chang B, Chan JH, Gregorio J, Coffman RL et al. Inhibitors of TLR-9 act on multiple cell subsets in mouse and man in vitro and prevent death in vivo from systemic inflammation. J Immunol 2005; 174: 5193-5200.

113 Erridge C, Kennedy S, Spickett CM, Webb DJ. Oxidized phospholipid inhibition of toll-like receptor (TLR) signaling is restricted to TLR2 and TLR4: roles for CD14, LPS-binding protein, and MD2 as targets for specificity of inhibition. J Biol Chem 2008; 283: 24748-24759. 
114 Zhou S, Cerny AM, Bowen G, Chan M, Knipe DM, Kurt-Jones EA et al. Discovery of a novel TLR2 signaling inhibitor with anti-viral activity. Antiviral Res 2010; 87: 295-306.

115 Davis CN, Mann E, Behrens MM, Gaidarova S, Rebek M, Rebek J Jr et al. MyD88-dependent and -independent signaling by IL-1 in neurons probed by bifunctional Toll/IL-1 receptor domain/BB-loop mimetics. Proc Nat/ Acad Sci USA 2006; 103: 2953-2958.

116 Loiarro M, Capolunghi F, Fanto N, Gallo G, Campo S, Arseni B et al. Pivotal advance: inhibition of MyD88 dimerization and recruitment of IRAK1 and IRAK4 by a novel peptidomimetic compound. J Leukocyte Biol 2007; 82: 801-810.

117 Butt AQ, Ahmed S, Maratha A, Miggin SM. 14-3-3\{Epsilon\} and 14-33sigma inhibit Toll-like receptor (TLR)-mediated proinflammatory cytokine induction. J Biol Chem 2012; 287: 38665-38679.

118 Chen Q, Wang H, Liu Y, Song Y, Lai L, Han Q et al. Inducible microRNA223 down-regulation promotes TLR-triggered IL- 6 and IL-1 beta production in macrophages by targeting STAT3. PLoS One 2012; 7: e42971.

119 Gonzalez-Lopez A, Aguirre A, Lopez-Alonso I, Amado L, Astudillo A, Fernandez-Garcia MS et al. MMP-8 deficiency increases TLR/RAGE ligands S100A8 and S100A9 and exacerbates lung inflammation during endotoxemia. PLoS One 2012; 7: e39940.

120 Ito $\mathrm{H}$, Hamerman JA. TREM-2, triggering receptor expressed on myeloid cell-2, negatively regulates TLR responses in dendritic cells. Eur J Immunol 2012; 42: 176-185.

121 Schneider M, Zimmermann AG, Roberts RA, Zhang L, Swanson KV, Wen $\mathrm{H}$ et al. The innate immune sensor NLRC3 attenuates Toll-like receptor signaling via modification of the signaling adaptor TRAF6 and transcription factor NF-kappaB. Nat Immunol 2012; 13: 823-831.

122 Basith S, Manavalan B, Lee G, Kim SG, Choi S. Toll-like receptor modulators: a patent review (2006-2010). Expert Opin Therap Patents 2011; 21: 927-944.

(c) (i) () $\ominus$ This work is licensed under a Creative Commons Attribution-NonCommercial-NoDerivs 3.0 Unported License. To view a copy of this license, visit http:// creativecommons.org/licenses/by-nc-nd/3.0/ 